\title{
Highly Dynamic PVP-Coated Silver Nanoparticles in Aquatic Environments: Chemical and Morphology Change Induced by Oxidation of $\mathrm{Ag}^{\mathbf{0}}$ and Reduction of $\mathrm{Ag}^{+}$
}

\author{
Su-juan Yu, ${ }^{\dagger}$ Yong-guang Yin, ${ }^{\dagger}$ Jing-bo Chao, ${ }^{\ddagger}$ Mo-hai Shen, ${ }^{\dagger}$ and Jing-fu Liu* ${ }^{\dagger}$ \\ ${ }^{\dagger}$ State Key Laboratory of Environmental Chemistry and Ecotoxicology, Research Center for Eco-Environmental Sciences, Chinese \\ Academy of Sciences, P.O. Box 2871, Beijing 100085, China \\ ${ }^{\ddagger}$ Chemical Metrology and Analytical Science Division, National Institute of Metrology, P. R. China, Beijing 100013
}

\section{Supporting Information}

\begin{abstract}
The fast growing and abundant use of silver nanoparticles (AgNPs) in commercial products alerts us to be cautious of their unknown health and environmental risks. Because of the inherent redox instability of silver, AgNPs are highly dynamic in the aquatic system, and the cycle of chemical oxidation of AgNPs to release $\mathrm{Ag}^{+}$and reconstitution to form AgNPs is expected to occur in aquatic environments. This study investigated how inevitable environmentally relevant factors like sunlight, dissolved organic matter (DOM), $\mathrm{pH}, \mathrm{Ca}^{2+} / \mathrm{Mg}^{2+}$, $\mathrm{Cl}^{-}$, and $\mathrm{S}^{2-}$ individually or in combination affect the chemical transformation of AgNPs. It was demonstrated that simulated sunlight induced the aggregation of AgNPs, causing particle fusion or self-assembly to form larger structures and aggregates.

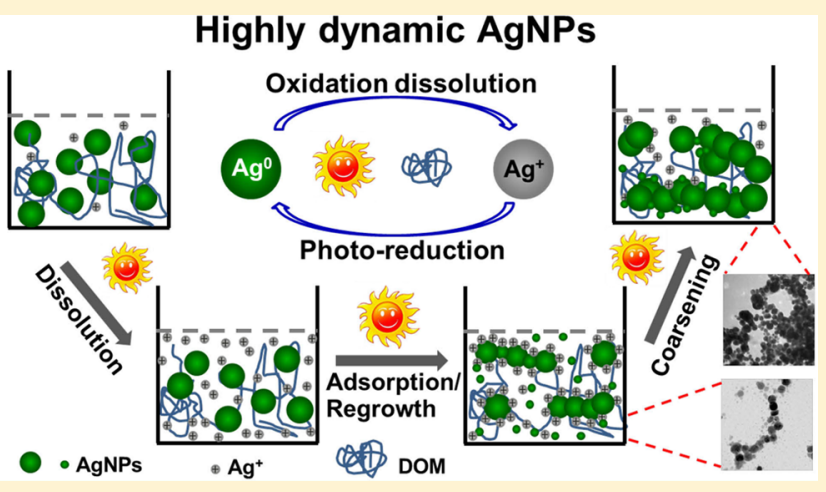
Meanwhile, AgNPs were significantly stabilized by DOM, indicating that AgNPs may exist as single particles and be suspended in natural water for a long time or delivered far distances. Dissolution (ion release) kinetics of AgNPs in sunlit DOM-rich water showed that dissolved $\mathrm{Ag}$ concentration increased gradually first and then suddenly decreased with external light irradiation, along with the regeneration of new tiny AgNPs. $\mathrm{pH}$ variation and addition of $\mathrm{Ca}^{2+}$ and $\mathrm{Mg}^{2+}$ within environmental levels did not affect the tendency, showing that this phenomenon was general in real aquatic systems. Given that a great number of studies have proven the toxicity of dissolved Ag (commonly regarded as the source of AgNP toxicity) to many aquatic organisms, our finding that the effect of DOM and sunlight on AgNP dissolution can regulate AgNP toxicity under these conditions is important. The fact that the release of $\mathrm{Ag}^{+}$and regeneration of AgNPs could both happen in sunlit DOM-rich water implies that previous results of toxicity studies gained by focusing on the original nature of AgNPs should be reconsidered and highlights the necessity to monitor the fate and toxicity of AgNPs under more environmentally relevant conditions.
\end{abstract}

\section{INTRODUCTION}

In the past few decades, an extensive and growing interest has been focused on the unique physical and chemical properties of nanomaterials, which has led to the increased production and application of nanoparticles (NPs) worldwide. ${ }^{1}$ Rapid advances in nanotechnology coupled with the known excellent antibacterial ability of silver nanoparticles (AgNPs) have encouraged their application in the biomedical field ${ }^{2}$ and incorporation in vast commercial products such as fabrics, ${ }^{3}$ disinfectants, ${ }^{4}$ and food packaging. ${ }^{5}$ Being at the highest degree of commercialization, AgNPs have held a prime place in the nanofamily.

The growing production and use of AgNPs has paralleled growing public concern of their potential risks to organisms and the human body, as it was evidenced that AgNPs would eventually find their way to the environment. The release of AgNPs from commercial textiles during washing and from outdoor facades after rainfall events was reported in several studies. ${ }^{3,6-8}$ Toxicology data also show that AgNPs can cause damage to different cell lines ${ }^{9,10}$ and be potentially toxic to a variety of organisms including plants, vertebrates, and mammals. ${ }^{11-15}$ Meanwhile, AgNPs are highly dynamic in the aqueous solution, ${ }^{16}$ and once released into the environment, they would undergo different chemical and morphology transformations during transport, which would in turn greatly affect their final fate, transport, and potential bioavailability and toxicity. ${ }^{17}$ In aquatic systems containing abundant electrolytes and Ag-complexing ligands, the undesirable formation of secondary precipitation, ${ }^{18}$ cross-linking structures, ${ }^{19}$ large aggregates, ${ }^{20}$ and recrystallization of small $\mathrm{NPs}^{21}$ are reported. However, the mechanism for triggering the transformation of

Received: September 28, 2013

Revised: December 9, 2013

Accepted: December 11, 2013

Published: December 11, 2013 
AgNPs is still not clear. We speculate that the dynamic behavior of AgNPs in the environment can be attributed to the medium redox potential of silver $\left(\varphi^{\Theta}\left(\mathrm{Ag}^{+} / \mathrm{Ag}^{0}\right)=0.80 \mathrm{~V}\right)$, which made it possible that the oxidation of $\mathrm{Ag}^{0}$ and reduction of $\mathrm{Ag}^{+}$could both occur in aquatic systems. Previous studies demonstrated that AgNPs could be easily oxidized in the presence of dissolved oxygen and protons, and high temperature greatly promoted the dissolution of $\mathrm{Ag}^{+} \cdot 22$ The particle size, initial concentration, and surface coating also influence this oxidative dissolution. ${ }^{23-27}$ On the other hand, natural organic matter (NOM), ubiquitous in the complex aquatic environments, created an ideal reductive compartment for $\mathrm{Ag}^{+}$because of the abundant functional groups like phenolic- $\mathrm{OH}$, quinones, hydroxyls, methoxyls, and ketones. Humic acid and fulvic acid from different sources were shown to induce the formation of AgNPs under environmentally relevant conditions, and elevated temperature $\left(90{ }^{\circ} \mathrm{C}\right)$ and $\mathrm{pH}$ (9.0) resulted in accelerated formation of AgNPs. ${ }^{28,29}$ Sunlight is also proven to be one of the determining factors affecting the formation of AgNPs in aquatic environments. ${ }^{30,31}$ AgNPs were observed in natural river water containing $\mathrm{AgClO}_{4}$ after several hours of solar exposure. Furthermore, it was also reported that new AgNPs were generated under ambient conditions at relative humidities greater than $50 \%,{ }^{32}$ implying that AgNPs could be produced spontaneously in nature.

Though chemical transformation of AgNPs has been reported in several studies, the key parameters influencing their final fate are still unclear. Most of these studies were conducted in relatively idealized systems and emphasized on the impact of a single environmental variable (e.g., temperature, $\mathrm{pH}$, concentration, particle size). Once in the natural system, it is unclear whether the behavior of NPs remains the same as that in the single variable environment. Considering the dynamic nature of AgNPs, the chemical oxidation of AgNPs to release $\mathrm{Ag}^{+}$and reconstitution to form AgNPs is expected to happen simultaneously in certain aquatic environments, which would potentially influence the transformation and subsequent toxicity of AgNPs.

In order to make a rational assessment on the environmental risks posed by AgNPs, further data about the transformation and speciation of AgNPs in the real environment are urgently required. In this study, we examine how environmentally relevant factors like NOM, sunlight, $\mathrm{Ca}^{2+} / \mathrm{Mg}^{2+}, \mathrm{Cl}^{-}$, and $\mathrm{S}^{2-}$ individually or in combination affect the chemical transformation of AgNPs. We showed that AgNPs are highly dynamic in the aquatic system, and once released into the natural system, the oxidation release of $\mathrm{Ag}^{+}$and reconstitution of AgNPs can both occur, along with significant morphology changes.

\section{MATERIALS AND METHODS}

Materials. $\mathrm{AgNO}_{3}(>99.5 \%)$ and hydroxylammonium chloride $\left(\mathrm{NH}_{2} \mathrm{OH} \cdot \mathrm{HCl},>98.5 \%\right)$ were purchased from Sinopharm Chemical Reagent Co. Ltd. (Shanghai, China). Polyvinylpyrrolidone (PVP, MW = 58 000) was purchased from Aladdin Chemistry Co. Ltd. (Shanghai, China). $\mathrm{HNO}_{3}$ (65\%) was purchased from Merck (Darmstadt, Germany). Suwannee river humic acid (SRHA) was from the International Humic Substances Society (IHSS, St. Paul, MN). The other reagents were purchased from Beijing Chemicals (Beijing, China). All the reagents were used as obtained without further purification. Ultrapure water $(18.3 \mathrm{M} \Omega)$ produced with a Milli-
Q Gradient system (Millipore, Billerica, MA) was used throughout the experiments.

Synthesis of the PVP-Coated AgNPs. AgNPs were synthesized following the method described by Lendl and Leopold $^{33}$ with slight modification. Briefly, $10 \mathrm{~mL}$ of $10 \mathrm{mM}$ $\mathrm{AgNO}_{3}$ was added into a $90 \mathrm{~mL}$ solution containing $1.67 \mathrm{mM}$ $\mathrm{NH}_{2} \mathrm{OH} \cdot \mathrm{HCl}$ and $3.33 \mathrm{mM} \mathrm{NaOH}$ under vigorous stirring, and the color turned yellow immediately. After several minutes, 0.3 $\mathrm{g}$ of PVP was introduced into the system and stirred for the whole night. The soluble byproducts were removed by centrifugal ultrafiltration (Amicon Ultra-15 $100 \mathrm{kD}$, Millipore, $\mathrm{MA}$ ), and AgNPs were further purified by water for three cycles, after which the stock solutions were stored at $4{ }^{\circ} \mathrm{C}$ in the dark for later use.

Characterization of AgNPs. Transmission electron microscopy (TEM) and energy dispersive X-ray spectroscopy (EDS) analysis were carried out with an H-7500 (Hitachi, Japan) at $80 \mathrm{kV}$ or a high resolution TEM coupled with an EDS (TECANI G20, FEI, Hillsboro OR) at $200 \mathrm{kV}$. TEM samples were prepared by placing $5 \mu \mathrm{L}$ aliquots of the aqueous sample onto an ultrathin carbon-coated copper grid and drying at room temperature. The UV-vis spectra from 300 to $800 \mathrm{~nm}$ were obtained by using a Shimadzu UV-3600 (Kyoto, Japan). The Zeta potential and hydrodynamic diameter of AgNPs were characterized by dynamic light scattering (DLS) with a Zetasizer Nano (Malvern Instruments, UK). Specifically, stock AgNP suspensions were diluted with ultrapure water to a final concentration of $10 \mathrm{mg} / \mathrm{L}$, and the results given were the average value of three measurements. The polydispersivity index (PDI), reported directly from the Zetasizer Nano ZS instrument when measuring the average hydrodynamic diameter, was also recorded to interpret the broadness of the size distribution. The total $\mathrm{Ag}$ concentration of $\mathrm{AgNP}$ stock solution and the contents of $\mathrm{Ag}^{+}$after separation were measured by Agilent 7700 ICP-MS (Santa Clara, CA), which was conducted with $\mathrm{Ag}$ standards and after $\mathrm{HNO}_{3}$ digestion.

Natural Organic Matter Solutions. SRHA was prepared at $1 \mathrm{~g} / \mathrm{L}$ in ultrapure water and dissolved overnight on an endover-end rotator at room temperature and then filtered through a $0.45 \mu \mathrm{m}$ membrane filter (mixed cellulose esters, Millipore, Billerica, MA). The dissolved organic carbon (DOC) was determined with a Phoenix 8000 total organic carbon analyzer (Tekmar-Dohrmann, Cincinnati, $\mathrm{OH}$ ).

The Light Irradiation Experiment. The experiments were conducted in a solar simulator (Beifanglihui Co., SN-500, Beijing) equipped with three $2500 \mathrm{~W}$ Xe lamps to simulate the sunlight. The irradiation intensity was maintained at $550 \mathrm{~W} / \mathrm{m}^{2}$ and a temperature of $38 \pm 2{ }^{\circ} \mathrm{C}$. Diluted AgNP solutions with or without SRHA were prepared in $500 \mathrm{~mL}$ FEP (fluorinated ethylene propylene) bottles (Nalgene, Rochester, NY). In each batch of experiments, the dark control was performed in FEP bottles wrapped by three layers of aluminum foil and then one layer of black plastic bags and placed in the same simulator under similar conditions to the light-exposed ones. At each time interval, $7 \mathrm{~mL}$ of the sample was taken from the bottle, and dissolved Ag was separated from AgNPs using the centrifugal ultrafilter devices (Amicon Ultra-15 $30 \mathrm{kD}$, Millipore, MA). After centrifugation at $5000 \mathrm{rpm}$ for $20 \mathrm{~min}$, the dissolved $\mathrm{Ag}$ in the filtrate was collected and mixed with $0.3 \mathrm{~mL}$ of $65 \% \mathrm{HNO}_{3}$ for ICP-MS analysis. It is worth it to mention that the dissolved $\mathrm{Ag}$ in our study refers to all the dissolved Ag species that could pass through the filtration membranes, including mainly free $\mathrm{Ag}^{+}$and SRHA associated $\mathrm{Ag}^{+}$, and possibly some tiny 

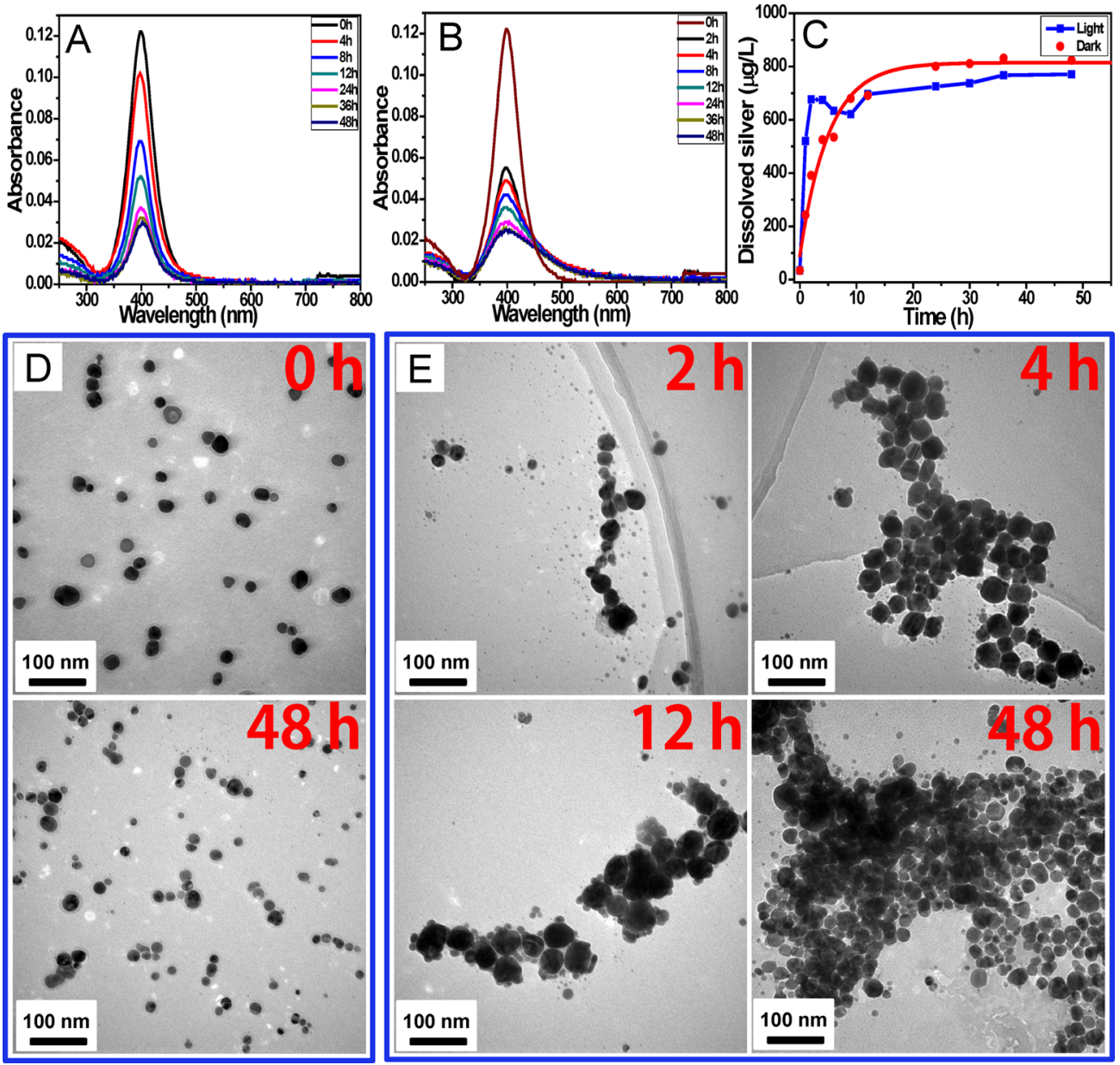

Figure 1. UV-vis absorption spectra, dissolution (ion release) kinetics, and TEM images of AgNPs (1.02 mg/L, pH 6.3) in the absence of DOM. (A) UV-vis spectra in the dark, (B) UV-vis spectra in the light, (C) dissolved Ag release curve, (D) TEM images in the dark at time intervals of 0 and $48 \mathrm{~h}$, (E) TEM images in the light at time intervals of 2, 4, 12, and $48 \mathrm{~h}$.

reproduced AgNPs (see Supporting Information). The upper solution, kept in the filter device, was used to prepare TEM samples to monitor the shape transformation of AgNPs. Another $3 \mathrm{~mL}$ of the sample was taken to measure the UV-vis spectra. All experiments were performed for at least duplicate samples. UV-vis spectra of AgNPs recorded before and after centrifugal ultrafiltration and the TEM image of the filtrate demonstrated the absence of AgNPs in the filtrate (Figure S1), and ICP-MS analysis showed that the recoveries of $\mathrm{Ag}^{+}$in the filtrate were between $80 \%$ and $90 \%$ for both in the presence and absence of HA (Figure S2).

\section{RESULTS AND DISCUSSION}

Characterization and Stability of AgNPs. TEM images showed that the synthesized PVP-coated AgNPs used in this study are spherical with an average diameter of $25.6 \pm 0.4 \mathrm{~nm}$ by counting over 150 individual particles (Figure S3). The NPs carried a strongly negative charge with a Zeta potential of $-33.0 \mathrm{mV}$ in ultrapure water at $\mathrm{pH}$ 6.3. In situ DLS gave a hydrodynamic diameter of $26.4 \mathrm{~nm}$ with a polydispersivity index (PDI) of 0.256 , showing that the AgNPs were relatively monodispersed. To further evaluate the stability of AgNPs used in our study, the stock solution kept at $4{ }^{\circ} \mathrm{C}$ for three months was also imaged by TEM and DLS, and no obvious change was observed, showing the AgNPs were quite stable.
Influence of Light Irradiation. Diluted AgNP solution $(1.02 \mathrm{mg} / \mathrm{L})$ was exposed to simulated sunlight or kept in the dark for $48 \mathrm{~h}$ to assess the solar irradiation on the transformation of AgNPs. UV-vis spectra of AgNPs in the dark (Figure 1A) showed that the SPR absorption at $\lambda_{\max }$ decreased as a function of time, representing the concentration of AgNPs reduced, probably due to the release of $\mathrm{Ag}^{+}$. During the investigation time, only a very slight blue shift of absorbance, $\lambda_{\max }$ from 401 to $397 \mathrm{~nm}$ occurred, indicating a decrease in particle size but no aggregation of particles. In contrast, the SPR absorption changed significantly after solar exposure (Figure 1B). A more apparent absorption reduction at $\lambda_{\max }$ and the broadening of the peak width were observed within $2 \mathrm{~h}$, suggesting possible aggregation of AgNPs.

We further measured AgNP dissolution kinetics under simulated sunlight. Before the solar irradiation, the initial $\mathrm{Ag}^{+}$ concentration measured in the diluted AgNP solution was 24 $\mu \mathrm{g} / \mathrm{L}$, which accounts for about $2.3 \%$ of the total silver content. The dissolved Ag in the dark increased quickly during the first $24 \mathrm{~h}$ (shown in Figure 1C) and then leveled off, which is in accord with previous ion release kinetic studies. ${ }^{23,26,27}$ However, silver ion release under light irradiation was initially high, and the dissolved Ag concentration reached a maximum value after about $2 \mathrm{~h}$ and then decreased continuously until $9 \mathrm{~h}$, followed by a gradual equilibrium. The fast dissolution of AgNPs during the first $2 \mathrm{~h}$ was mostly ascribed to the photo- 

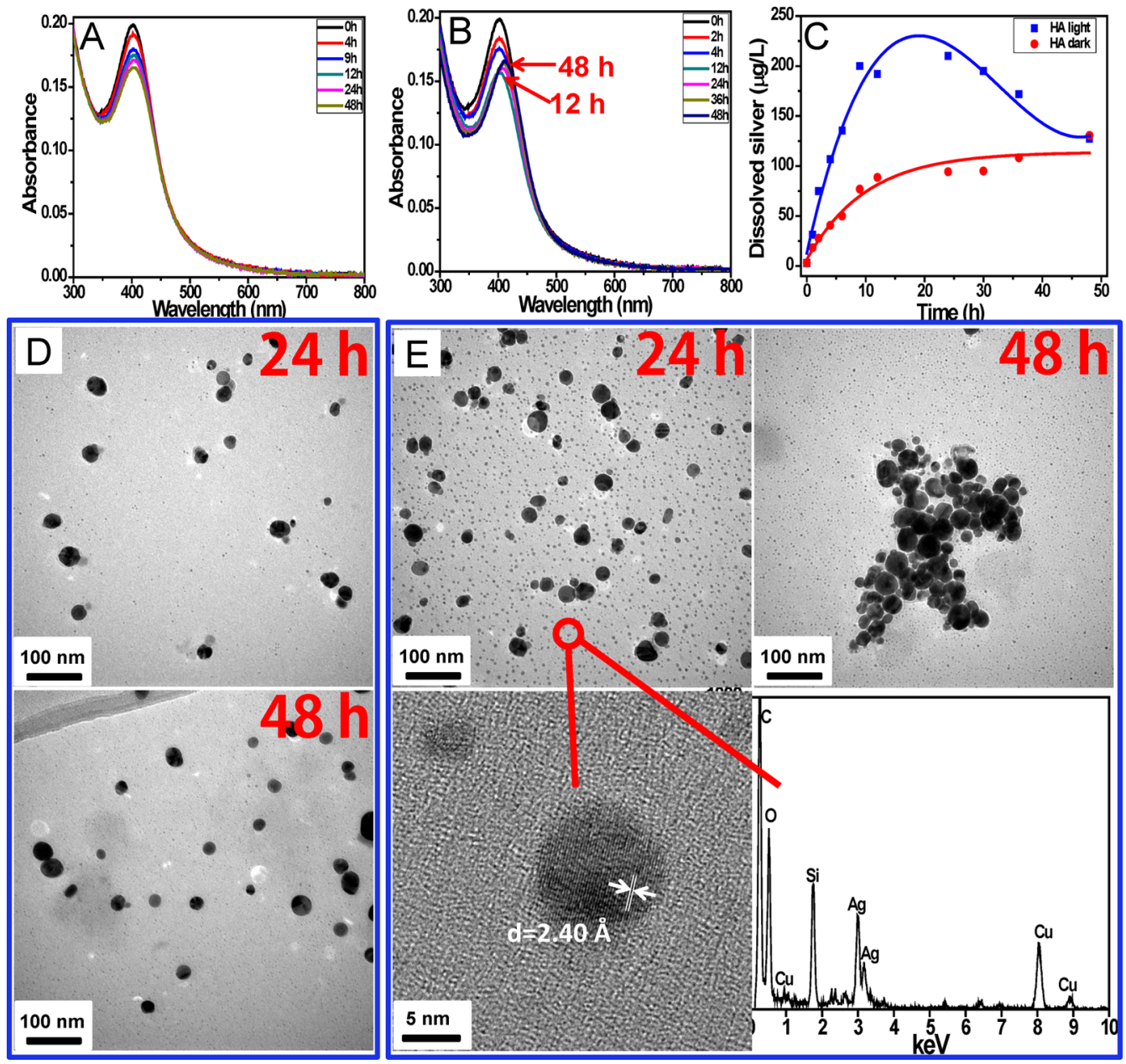

Figure 2. UV-vis absorption spectra, dissolution (ion release) kinetics, TEM images, and EDX analysis of AgNPs in the presence of SRHA. 1.02 $\mathrm{mg} / \mathrm{L}$ AgNPs, $5 \mathrm{mg} \mathrm{C}$ /L SRHA, pH 6.3. (A) UV-vis spectra in the dark, (B) UV-vis spectra in the light, (C) dissolved Ag release curve, (D) TEM images in the dark at time intervals of 24 and $48 \mathrm{~h}$, (E) TEM images in the light at time intervals of 24 and $48 \mathrm{~h}$, and the HRTEM and EDX of the new AgNPs.

oxidation of individual AgNPs. ${ }^{34}$ The decrease of $\mathrm{Ag}^{+}$ concentration in the time course of $2-9 \mathrm{~h}$ was attributed to the formation of a new generation of AgNPs. As the $\mathrm{Ag}^{+}$ concentration increased to a critical nucleation concentration, formation and precipitation of new AgNPs occurred, which decrease the $\mathrm{Ag}^{+}$concentration. TEM images (Figure 1E) showed that some ultrafine particles appeared around the original AgNPs after $2 \mathrm{~h}$, confirming the reduction of $\mathrm{Ag}^{+}$. The growth of new AgNPs and oxidation of AgNPs to release $\mathrm{Ag}^{+}$ probably occurred at the same time, and after $9 \mathrm{~h}$ the release of $\mathrm{Ag}^{+}$might dominate the process, which gave rise to an increase of the dissolved silver again. The reduction of $\mathrm{Ag}^{+}$to AgNPs was attributed to the photooxidation of PVP (the capping agent of AgNPs) under light irradiation, which produced degradation products with enhanced reducing ability. ${ }^{35}$ The photodegradation of PVP was also confirmed by the change of transparent PVP solutions to yellow, and the evolution of a new band centered at $439 \mathrm{~nm}$ in the UV-vis spectra after a few hours of irradiation (Figure S4). $\mathrm{The}^{\mathrm{Ag}^{+}}$release in the dark $(830 \mu \mathrm{g} / \mathrm{L})$ after $48 \mathrm{~h}$ was slightly higher than that under the solar irradiation $(738 \mu \mathrm{g} / \mathrm{L})$, which agreed with the literature. ${ }^{36}$ Though some large aggregates were formed under irradiation, no precipitation was observed. We speculate that the particles were probably loosely connected, which has no significant influence on the surface areas exposed to oxygen and therefore $\mathrm{Ag}^{+}$release.

TEM images (Figure $1 \mathrm{D}$ and E) were taken at different sampling times to assess the morphology change of AgNPs. While dispersed AgNPs in the dark was observed with only a little decrease in size $(18.1 \pm 0.6 \mathrm{~nm}$ vs $25.6 \pm 0.4 \mathrm{~nm})$ after 48 h, AgNPs under light irradiation showed substantial morphology change. As the weight and the radius of a spherical particle are related by the third power, the reduction of particle diameter from $26 \mathrm{~nm}$ (Figure 1D, $0 \mathrm{~h}$ ) to $18 \mathrm{~nm}$ (Figure 1D, 48 h) suggests a release of $\sim 67 \%$ silver in ionic form. This roughly agreed with the measured release of $\mathrm{Ag}^{+}(\sim 80 \%)$ calculated from the $\mathrm{Ag}^{+}$in the solution (Figure 1C). The difference between these two data ( $67 \%$ vs $80 \%)$ was attributed to the fact that the diameter counted by TEM images was just a rough estimation of the average size of AgNPs, while different sized NPs have distinct ion release kinetics, and small particles with a greater fraction of atoms at edges and corners than the large ones would dissolve to release Ag ions first in solutions. The size decrease of AgNPs caused by the release of ionic silver during storage was also reported by Kittler et al., ${ }^{23}$ in which the diameter of PVP-stabilized AgNPs was found to reduce from 84 to $56 \mathrm{~nm}$ after being stored for 35 days. After being exposed to light for $2 \mathrm{~h}$, the spherical AgNPs tended to aggregate and link 
together to form chain-like structure, which is in line with the peak broadening in SPR data (Figure 1B). Small particles, which were not found in the pristine solution, were observed in immediate vicinity of the parent particles, probably due to the photoreduction of dissolved $\mathrm{Ag}^{+}$. With prolonging reaction duration, the aggregate continued to grow, and particles fused to become bigger ones along with the small particles grown on the surface. A close examination of Figure 1D shows that also some small AgNPs appeared after $48 \mathrm{~h}$ in the dark, which might be attributed to the reduction of $\mathrm{Ag}^{+}$by the stabilizer PVP.

Light-induced shape transformation of AgNPs was also presented in other studies. Bare AgNPs and citrate-coated AgNPs showed obvious aggregation under solar exposure in natural waters. ${ }^{18}$ A similar phenomenon was also observed in Cheng's study, in which PVP-capped AgNPs formed chain-like structures while GA-capped AgNPs even precipitated out due to the different binding strengths of coating agents. ${ }^{19}$ The strong oscillating dipole-dipole interaction of AgNPs under sunlight was believed to induce NP destabilization. Moreover, sufficient capping ligand removal was reported to result in nanocrystal coalesce to form two-dimensional arrays. ${ }^{37}$ In our case, though excess PVP was added during the synthesis process, the repeated centrifugation process would remove most of it, and the binding energy between PVP and AgNPs might be weaker due to the input of thermal energy from the light. ${ }^{19}$ A recent study highlighted the effect of light on the formation and shape transformation of AgNPs under environmentally relevant conditions. ${ }^{30}$ Spherical AgNPs, initially formed by reducing $\mathrm{Ag}^{+}$in the presence of humic acid and simulated sunlight, transformed to plate-like Ag triangles and hexagons and then rod-like structures and even settled out with longer treatment time. ${ }^{30}$ As NOM was photoreactive, the photodegradation of NOM under extended light irradiation was suggested to lead to the morphology change of NOM capped AgNPs. Given that aqueous solutions of PVP could also be photo-oxidized under mild conditions, ${ }^{38}$ we speculate that photodegradation of PVP was another cause of the instability of AgNPs in our study. Furthermore, the formation of small NPs could also enhance the aggregation of large NPs by bridging flocculation, which was reported in a recent article. ${ }^{39}$

Influence of Dissolved Organic Matter (DOM). It is well established that humic acid (HA) could easily adsorb on the surface of NPs, and the electrostatic and steric forces will prevent NPs from coalescence, which would help to stabilize NPs, and influence or even control the transport of NPs in natural aquatic systems. ${ }^{40-42}$ Moreover, the abundant functional groups of HA have drawn growing interest in pursuing their potential role in the chemical transformation of NPs. Herein, SRHA (at an environmentally relevant concentration, 5 $\mathrm{mg} \mathrm{C} / \mathrm{L}$ ) was added in our system to assess the effects of NOM on the behavior of AgNPs in the light. As shown in Figure 2A and $\mathrm{B}$, the UV-vis absorbance spectra in the dark and light did not change much during the experiment process except that the SPR absorption at $\lambda_{\max }$ declined with time. Compared with the significant peak broadening after $2 \mathrm{~h}$ in the light in the absence of HA (Figure 1B), the AgNP stability was enhanced significantly in the presence of SRHA. It is noteworthy that in the presence of HA the UV-vis spectra in the light showed a dramatic change after $12 \mathrm{~h}$; i.e. the absorbance intensity began to increase steadily, accompanied by the $\lambda_{\max }$ red-shifted to some extent (Figure 2B), indicating that the AgNP concentration increased along with a little size coarsening.
In the presence of SRHA, the AgNP dissolution was also greatly reduced both in the dark and in the light (Figure $2 \mathrm{C}$ vs 1C), probably because NOM entangled with the PVP and inhibited release of $\mathrm{Ag}^{+}$from $\mathrm{AgNPs}$ or reversible reduction of $\mathrm{Ag}^{+}$to $\mathrm{Ag}^{0}$ by humic acids. ${ }^{22}$ Figure $2 \mathrm{C}$ also shows that the AgNP dissolution in the light increased gradually during the first $12 \mathrm{~h}$ and then decreased with prolonged irradiation, which agreed with the SPR result and has never been reported before. Though a few studies ${ }^{22,24-27}$ reported that size, surface coating, temperature, and many other factors affect the ion release kinetics of AgNPs, all of the results displayed that the oxidation rate of AgNPs slowed down and the concentration of dissolved Ag kept constant after a fast increasing in the initial time. Our earlier work $^{31}$ demonstrated that AgNPs could be formed within several hours in sunlit DOM-rich water, which is also reported in a recent study ${ }^{30}$ evaluating the reduction of $\mathrm{AgClO}_{4}$ by NOM under environmentally relevant light conditions. Thus, we speculated that the decrease of dissolved Ag can be ascribed to the reduction of $\mathrm{Ag}^{+}$to generate AgNPs by SRHA under light.

The morphology change of AgNPs in the presence of SRHA was further investigated by TEM. Figure $2 \mathrm{E}$ shows that there were a great number of small NPs appearing in the solution after $24 \mathrm{~h}$ in the light. A higher resolution TEM image revealed that the lattice fringe spacing of these small NPs was $2.40 \AA$ (by counting more than 20 lattice spacing three times to get the average value), which is consistent with the (111) lattice planes of the fcc structure of metallic silver. EDS analysis also showed the presence of a strong signal of $\mathrm{Ag}$, confirming that the small particles were nanosilver. The high contents of carbon, oxygen, and copper were ascribed to the carbon supported copper grid. The signal of silicon might come from the background of the instrument or the grid, as a strong peak of silicon was also observed in areas without samples. After irradiation for $48 \mathrm{~h}$, some NPs got close and tended to fuse together, which matches with the $\lambda_{\max }$ red-shifted in the UV-vis spectra results. A related study ${ }^{43}$ reported the appearing of a void peak in field flow fractionation fractograms after AgNP solution was exposed to UV irradiation in the presence of DOM, also implying small AgNPs produced via reduction of dissolved $\mathrm{Ag}^{+}$. AgNPs kept in the dark dispersed well all the time, but a close look could also observe a few tiny AgNPs in the TEM images (Figure 2D), and the number was much less than its counterpart in the light, suggesting that $\mathrm{Ag}^{+}$could also be reduced by NOM without solar irradiation, ${ }^{44}$ though this process was much slower.

Influence of $\mathrm{pH}$. To determine whether the transformation of AgNPs in sunlit DOM-rich water is a more general phenomenon in the environment, we investigated the UVvis spectra and dissolution at different $\mathrm{pH}$ values $(\mathrm{pH}$ 5-8.5), which would encompass most natural surface and groundwater conditions. The UV-vis spectra of AgNPs under different conditions (Figure S5A-F) show that all of the AgNPs in the light exhibited the same tendency; namely, the absorbance intensity began to increase after 12 or $24 \mathrm{~h}$ decline, and this transformation is much more obvious at high $\mathrm{pH}$. The timeresolved concentration of dissolved silver (Figure 3 ) is also highly $\mathrm{pH}$-dependent; i.e., the $\mathrm{Ag}$ release was much more excessive at $\mathrm{pH} 5.0$ than that at higher $\mathrm{pHs}$. As the oxidation of AgNPs is a cooperative process involving both dissolved $\mathrm{O}_{2}$ and protons, ${ }^{22}$ lower $\mathrm{pH}$ would largely enhance the dissolution of AgNPs to form $\mathrm{Ag}^{+}$. On the other hand, the regeneration of AgNPs was also closely related with $\mathrm{pH}$ values, with the curve of dissolved silver declining to the lowest level at $\mathrm{pH}$ 8.4. Our 


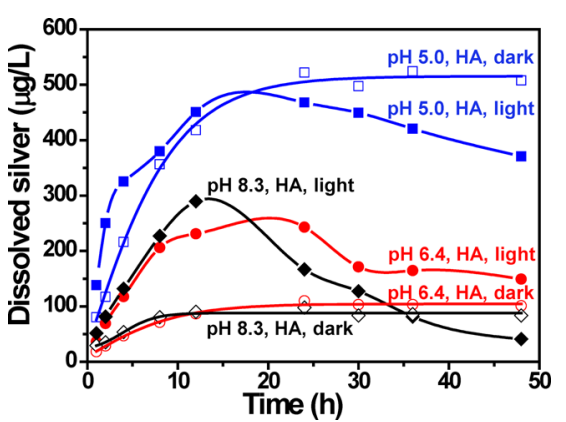

Figure 3. Dissolution (ion release) kinetics of AgNPs (1.02 mg/L) in the presence of $5 \mathrm{mg} \mathrm{C} / \mathrm{L}$ SRHA at different $\mathrm{pH}$ values.

early study ${ }^{31}$ has reported that there was a linear relationship between the redox potential of HA solution and $\mathrm{pH}$. The lower redox potential of $\mathrm{HA}$ at high $\mathrm{pH}$ has a stronger ability to reduce $\mathrm{Ag}^{+}$, accounting for the evident decrease of dissolved silver. These results suggest that this production of $\mathrm{Ag}^{+}$from oxidation dissolution of AgNPs and regeneration of AgNPs from the $\mathrm{Ag}^{+}$process may commonly occur for AgNPs in the aquatic environment. Our finding provides significant new insights into the highly dynamic and related toxicity of AgNPs. Though the mechanism of AgNP toxicity is still under debate, there is a general recognition that the toxicity is closely related with the $\mathrm{Ag}^{+}$concentration in solutions, ${ }^{13,45,46}$ and the particle size affected the potential toxicity as well. ${ }^{47,48}$ Aged AgNPs were more toxic to cells than fresh ones because of the increased amount of $\mathrm{Ag}^{+}$during storage. ${ }^{23}$ It was also presented that AgNP toxicity was reduced by light, and this toxicity change was size-dependent; i.e., the decrease in toxicity was much more obvious for small particles. ${ }^{36}$ Moreover, the sizerelated uptake of silver in Daphnia magna was observed for both citrate and tannic acid coated AgNPs, suggesting that particle size highly influenced the bioavailability of AgNPs. ${ }^{49}$ Since our results showed that the dissolved $\mathrm{Ag}$ concentration may decline after some time in the real environment and containing DOM and various small NPs or NP aggregates may form in the exposure process, we infer that the related toxicity of AgNPs would change at the same time, so differentiating the
AgNP hazards by their initial sizes could be misleading and highlight the necessity to monitor the fate and toxicity of AgNPs under more environmentally relevant conditions.

Influence of $\mathrm{Ca}^{2+}$ and $\mathbf{M g}^{2+}$. Ionic composition, especially divalent cations like $\mathrm{Ca}^{2+}$ and $\mathrm{Mg}^{2+}$, greatly affect the stability, ion release, and transport of AgNPs. ${ }^{50-52}$ To pursue the real transformation of AgNPs in the environment, $\mathrm{Ca}\left(\mathrm{NO}_{3}\right)_{2}$ and $\mathrm{Mg}\left(\mathrm{NO}_{3}\right)_{2}$ under environmentally relevant concentrations were spiked in AgNP solutions in the presence of SRHA. It was shown that the UV-vis spectra of AgNPs in the dark did not change much, except for a little decrease in the $\lambda_{\max }$ absorbance intensity (Figure S6A), indicating AgNPs kept stable in the solution. This agreed with the literature reported critical coagulation concentration (CCC) of PVP-coated AgNPs, which was $4.9 \mathrm{mM}$ for $\mathrm{Ca}^{2+}$ and even higher in the presence of HA. ${ }^{53}$ In the light, however, AgNPs underwent aggregation after longer exposure as a new peak at a higher wavelength appeared (Figure S6B), which again suggested the nonnegligible effect of solar irradiation. Dissolution kinetics of AgNPs in the presence of $\mathrm{Ca}^{2+}$ and $\mathrm{Mg}^{2+}$ (Figure S6C) did not show much difference with that shown in Figure 4 (curves of $\mathrm{pH} 8.3$ ), indicating that a low concentration of divalent cations did not significantly affect the chemical transformation of AgNPs.

Influence of $\mathrm{Cl}^{-}$and $\mathrm{S}^{2-}$. Strong ligands, such as $\mathrm{Cl}^{-}$and $\mathrm{S}^{2-}$, were reported to remarkably influence the environmental transformation of AgNPs. ${ }^{54-56}$ Thus, $\mathrm{Cl}^{-}$and $\mathrm{S}^{2-}$ under environmentally relevant concentrations were also added, respectively, in AgNP solutions containing NOM to investigate the behavior of AgNPs. As seen in Figures S7 and S8, the dissolution rates showed a strong decrease in the presence of $\mathrm{Cl}^{-}$or $\mathrm{S}^{2-}$ (compared with Figure 2), which is also reported in the previous literature. ${ }^{54,55}$ The strong affinity of $\mathrm{Ag}^{+}$toward $\mathrm{Cl}^{-}$and $\mathrm{S}^{2-}$ would form $\mathrm{AgCl}$ and $\mathrm{Ag}_{2} \mathrm{~S}$ grains, which may precipitate on the surface of AgNPs to block their further oxidation. ${ }^{51}$ Though the dissolution of AgNPs decreased sharply in the presence of $\mathrm{Cl}^{-}$or $\mathrm{S}^{2-}$, we still found a reduction of dissolved silver concentration after long solar irradiation, indicating that the reconstitution of AgNPs also occurred.

\section{Pathway for the transformation of AgNPs}

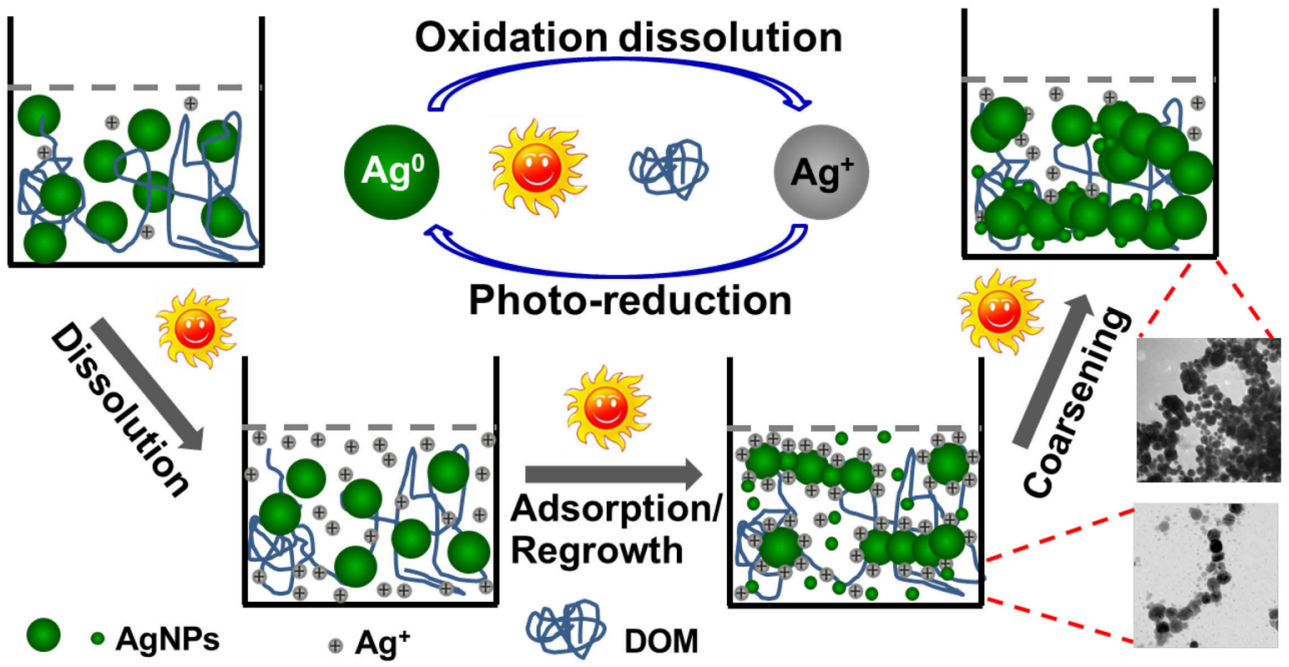

Figure 4. Proposed pathway for the transformation of AgNPs in aquatic environments. 
Stability of AgNPs under Sunlight. To demonstrate the long-term effects of sunlight and other combined factors, AgNP solutions with higher concentrations were prepared in a different matrices (including deionized water, SRHA solution, SRHA solution containing $\mathrm{Ca}^{2+}$ and $\mathrm{Mg}^{2+}$ ) and placed under natural sunlight or kept in the dark for 15 days. The digital image of the suspensions and their related UV-vis spectra are given in Figure S9. AgNPs in deionized water suffered from apparent aggregation under sunlight irradiation, as the color turned from yellow to gray and a new absorption peak appeared at a higher wavelength. However, no precipitate was observed, suggesting that the aggregates were still stable in solution. In contrast, the same solution kept in the dark did not show any obvious change in peak position, revealing that the AgNPs dispersed well in the dark. AgNPs in the presence of SRHA seemed to be much more stable under both light and dark conditions, though AgNPs in the dark underwent more dissolution. This means AgNPs in solutions containing HA may stay as stable particles for a long time in an aquatic environment, which is also reported in previous studies for both AgNPs and other NPs. ${ }^{28,29,57-60}$ AgNP solutions with HA, $\mathrm{Ca}^{2+}$, and $\mathrm{Mg}^{2+}$ gradually precipitated to the bottom of the vials, especially the one under solar exposure. The suspension became almost transparent, and no absorption peak was observed in the UV-vis spectra.

On the basis of the results described above, we proposed a three-stage pathway for the transformation of AgNPs under light irradiation (Figure 4). In the first stage, light induced photodegradation of the capping agent PVP and resulted in the fast oxidation of AgNPs and abundant release of dissolved Ag. The second stage included the readsorption of $\mathrm{Ag}^{+}$on the AgNP surface and reformation of small particles. Ag ions, diffused away from the parent particles, would form new NPs around or far away from the parent particles. ${ }^{32}$ Meanwhile, reduction of adsorbed $\mathrm{Ag}^{+}$on the surface of AgNPs may generate nanobridges to connect nearby particles together, ${ }^{55}$ causing particle fusion or self-assembly to form larger structures. In the third stage, many more NPs were involved in the cross-linking structures, and small particles also grew on the surface of bigger ones, forming large aggregates and precipitation of Ag nanostructures.

Environmental Implications. Our study demonstrated that AgNPs were highly dynamic in aquatic systems. When subjected to inevitable environmentally relevant factors such as sunlight, DOM, $\mathrm{Ca}^{2+}$, and $\mathrm{Mg}^{2+}$, AgNPs would undergo oxidation and reduction simultaneously, along with $\mathrm{Ag}^{+}$release, secondary NP regeneration, and various morphology changes, from dispersed spherical NPs to larger connected structures, large aggregates, and tiny particles, or would even settle down. These chemical species and morphology alterations greatly impact the final fate, transport, potential bioavailability, and toxicity of AgNPs. Particle size is shown to influence the ion release, uptake, and toxicity of AgNPs. ${ }^{26,48,49}$ Considering that a large number of small AgNPs were generated in DOM-rich water under sunlight, elevated bioavailability of AgNPs and silver accumulation in organisms are expected. Large aggregates could form after prolonged sunlight irradiation, especially in the presence of $\mathrm{Ca}^{2+}$ and $\mathrm{Mg}^{2+}$, and the precipitates would sink and deposit in the sediment, which may pose a renewed risk to the benthic species. Given that DOM significantly enhances the stability of AgNPs, AgNPs may exist as single particles and may be suspended in natural water for a long time or delivered far distances in aquatic systems that contain high concentrations of
DOM, showing a persistent hazard to fish and aquatic invertebrates. Most important of all, given that a great number of studies have proven the dissolved Ag (commonly regarded as the source of AgNP toxicity) was toxic to many aquatic organisms, our finding that the AgNP dissolution gradually decreased after some time in sunlit DOM-rich water indicates that the toxicity of AgNPs may diminish to a certain degree.

In real aquatic environments, the expected AgNP concentration was much lower than that used in our study. Blaser et al. ${ }^{61}$ have estimated that the predicted environmental concentration of AgNPs in the river was $30-320 \mathrm{ng} / \mathrm{L}$ in the maximum scenarios, and the presence of strong ligands such as $\mathrm{Cl}^{-}$and $\mathrm{S}^{2-}$ would further decrease this value. Further exploring of the behavior of AgNPs in more real and complex systems is needed to better understand the fate of AgNPs in natural waters.

\section{ASSOCIATED CONTENT}

\section{Supporting Information}

Experimental details and additional results are provided. This material is available free of charge via the Internet at http:// pubs.acs.org.

\section{AUTHOR INFORMATION}

\section{Corresponding Author}

*Tel.: +86-10-62849192. Fax: +86-10-62849192. E-mail: jfliu@ rcees.ac.cn.

\section{Notes}

The authors declare no competing financial interest.

\section{ACKNOWLEDGMENTS}

This work was supported by the National Basic Research Program of China (2010CB933502), the National Natural Science Foundation of China (21025729, 21227012, 21337004), and Research Center for Eco-environmental Sciences (RCEES-QN-20130028F).

\section{REFERENCES}

(1) Maynard, A. D.; Aitken, R. J.; Butz, T.; Colvin, V.; Donaldson, K.; Oberdorster, G.; Philbert, M. A.; Ryan, J.; Seaton, A.; Stone, V.; Tinkle, S. S.; Tran, L.; Walker, N. J.; Warheit, D. B. Safe handling of nanotechnology. Nature 2006, 444 (7117), 267-269.

(2) Chaloupka, K.; Malam, Y.; Seifalian, A. M. Nanosilver as a new generation of nanoproduct in biomedical applications. Trends Biotechnol. 2010, 28 (11), 580-588.

(3) Benn, T. M.; Westerhoff, P. Nanoparticle silver released into water from commercially available sock fabrics. Environ. Sci. Technol. 2008, 42 (11), 4133-4139.

(4) Nazarenko, Y.; Han, T. W.; Lioy, P. J.; Mainelis, G. Potential for exposure to engineered nanoparticles from nanotechnology-based consumer spray products. J. Exposure Sci. Environ. Epidemiol. 2011, 114.

(5) Loher, S.; Schneider, O. D.; Maienfisch, T.; Bokorny, S.; Stark, W. J. Micro-organism-triggered release of silver nanoparticles from biodegradable oxide carriers allows preparation of self-sterilizing polymer surfaces. Small 2008, 4 (6), 824-832.

(6) Geranio, L.; Heuberger, M.; Nowack, B. The behavior of silver nanotextiles during washing. Environ. Sci. Technol. 2009, 43 (21), 8113-8118.

(7) Kaegi, R.; Sinnet, B.; Zuleeg, S.; Hagendorfer, H.; Mueller, E.; Vonbank, R.; Boller, M.; Burkhardt, M. Release of silver nanoparticles from outdoor facades. Environ. Pollut. 2010, 158, 2900-2905.

(8) Kulthong, K.; Srisung, S.; Boonpavanitchakul, K.; Kangwansupamonkon, W.; Maniratanachote, R. Determination of 
silver nanoparticle release from antibacterial fabrics into artificial sweat. Part. Fibre Toxicol. 2010, 7, 8-16.

(9) AshaRani, P. V.; Mun, G. L. K.; Hande, M. P.; Valiyaveettil, S. Cytotoxicity and genotoxicity of silver nanoparticles in human cells. ACS Nano 2009, 3 (2), 279-290.

(10) Kawata, K.; Osawa, M.; Okabe, S. In vitro toxicity of silver nanoparticles at noncytotoxic doses to HepG2 human hepatoma cells. Environ. Sci. Technol. 2009, 43 (15), 6046-6051.

(11) Lee, K. J.; Nallathamby, P. D.; Browning, L. M.; Osgood, C. J.; $\mathrm{Xu}, \mathrm{X} . \mathrm{H}$. N. In vivo imaging of transport and biocompatibility of single silver nanoparticles in early development of zebrafish embryos. ACS Nano 2007, 1 (2), 133-143.

(12) Navarro, E.; Piccapietra, F.; Wagner, B.; Marconi, F.; Kaegi, R.; Odzak, N.; Sigg, L.; Behra, R. Toxicity of silver nanoparticles to Chlamydomonas reinhardtii. Environ. Sci. Technol. 2008, 42 (23), 8959-8964.

(13) Yang, X. Y.; Gondikas, A. P.; Marinakos, S. M.; Auffan, M.; Liu, J.; Hsu-Kim, H.; Meyer, J. N. Mechanism of silver nanoparticle toxicity is dependent on dissolved silver and surface coating in Caenorhabditis elegans. Environ. Sci. Technol. 2012, 46 (2), 1119-1127.

(14) Yin, L. Y.; Cheng, Y. W.; Espinasse, B.; Colman, B. P.; Auffan, M.; Wiesner, M.; Rose, J.; Liu, J.; Bernhardt, E. S. More than the ions: The effects of silver nanoparticles on Lolium multiflorum. Environ. Sci. Technol. 2011, 45 (6), 2360-2367.

(15) Yu, S. J.; Yin, Y. G.; Liu, J. F. Silver nanoparticles in the environment. Environ. Sci.: Processes Impacts 2013, 15 (1), 78-92.

(16) Wiesner, M. R.; Lowry, G. V.; Casman, E.; Bertsch, P. M.; Matson, C. W.; Di Giulio, R. T.; Liu, J.; Hochella, M. F., Jr. Meditations on the ubiquity and mutability of nano-sized materials in the environment. ACS Nano 2011, 5 (11), 8466-8470.

(17) Levard, C.; Hotze, E. M.; Lowry, G. V.; Brown, G. E. Environmental transformations of silver nanoparticles: Impact on stability and toxicity. Environ. Sci. Technol. 2012, 46 (13), 6900-6914.

(18) Li, X.; Lenhart, J. J. Aggregation and dissolution of silver nanoparticles in natural surface water. Environ. Sci. Technol. 2012, 46 (10), 5378-5386.

(19) Cheng, Y. W.; Yin, L. Y.; Lin, S. H.; Wiesner, M.; Bernhardt, E.; Liu, J. Toxicity reduction of polymer-stabilized silver nanoparticles by sunlight. J. Phys. Chem. C 2011, 115 (11), 4425-4432.

(20) Unrine, J. M.; Colman, B. P.; Bone, A. J.; Gondikas, A. P.; Matson, C. W. Biotic and abiotic interactions in aquatic microcosms determine fate and toxicity of $\mathrm{Ag}$ nanoparticles. Part 1. Aggregation and dissolution. Environ. Sci. Technol. 2012, 46 (13), 6915-6924.

(21) Tejamaya, M.; Roemer, I.; Merrifield, R. C.; Lead, J. R. Stability of citrate, PVP, and PEG coated silver nanoparticles in ecotoxicology media. Environ. Sci. Technol. 2012, 46 (13), 7011-7017.

(22) Liu, J. Y.; Hurt, R. H. Ion release kinetics and particle persistence in aqueous nano-silver colloids. Environ. Sci. Technol. 2010, 44 (6), 2169-2175.

(23) Kittler, S.; Greulich, C.; Diendorf, J.; Koller, M.; Epple, M. Toxicity of silver nanoparticles increases during storage because of slow dissolution under release of silver ions. Chem. Mater. 2010, 22 (16), 4548-4554.

(24) Li, Y.; Zhang, W.; Niu, J.; Chen, Y. Surface-coating-dependent dissolution, aggregation, and reactive oxygen species (ROS) generation of silver nanoparticles under different irradiation conditions. Environ. Sci. Technol. 2013, 47 (18), 10293-10301.

(25) Liu, J. Y.; Sonshine, D. A.; Shervani, S.; Hurt, R. H. Controlled release of biologically active silver from nanosilver surfaces. ACS Nano 2010, 4 (11), 6903-6913.

(26) Ma, R.; Levard, C.; Marinakos, S. M.; Cheng, Y. W.; Liu, J.; Michel, F. M.; Brown, G. E.; Lowry, G. V. Size-controlled dissolution of organic-coated silver nanoparticles. Environ. Sci. Technol. 2012, 46 (2), $752-759$.

(27) Zhang, W.; Yao, Y.; Sullivan, N.; Chen, Y. S. Modeling the primary size effects of citrate-coated silver nanoparticles on their ion release kinetics. Environ. Sci. Technol. 2011, 45 (10), 4422-4428.

(28) Adegboyega, N. F.; Sharma, V. K.; Siskova, K.; Zboril, R.; Sohn, M.; Schultz, B. J.; Banerjee, S. Interactions of aqueous $\mathrm{Ag}^{+}$with fulvic acids: Mechanisms of silver nanoparticle formation and investigation of stability. Environ. Sci. Technol. 2013, 47 (2), 757-764.

(29) Akaighe, N.; MacCuspie, R. I.; Navarro, D. A.; Aga, D. S.; Banerjee, S.; Sohn, M.; Sharma, V. K. Humic acid-induced silver nanoparticle formation under environmentally relevant conditions. Environ. Sci. Technol. 2011, 45 (9), 3895-3901.

(30) Hou, W. C.; Stuart, B.; Howes, R.; Zepp, R. G. Sunlight-driven reduction of silver ions by natural organic matter: Formation and transformation of silver nanoparticles. Environ. Sci. Technol. 2013, 47 (14), 7713-7721.

(31) Yin, Y. G.; Liu, J. F.; Jiang, G. B. Sunlight-induced reduction of ionic $\mathrm{Ag}$ and $\mathrm{Au}$ to metallic nanoparticles by dissolved organic matter. ACS Nano 2012, 6 (9), 7910-7919.

(32) Glover, R. D.; Miller, J. M.; Hutchison, J. E. Generation of metal nanoparticles from silver and copper objects: Nanoparticle dynamics on surfaces and potential sources of nanoparticles in the environment. ACS Nano 2011, 5 (11), 8950-8957.

(33) Leopold, N.; Lendl, B. A new method for fast preparation of highly surface-enhanced Raman scattering (SERS) active silver colloids at room temperature by reduction of silver nitrate with hydroxylamine hydrochloride. J. Phys. Chem. B 2003, 107 (24), 5723-5727.

(34) Grillet, N.; Manchon, D.; Cottancin, E.; Bertorelle, F.; Bonnet, C.; Broyer, M.; Lerme, J.; Pellarin, M. Photo-oxidation of individual silver nanoparticles: A real-time tracking of optical and morphological changes. J. Phys. Chem. C 2013, 117 (5), 2274-2282.

(35) Hoppe, C. E.; Lazzari, M.; Pardinas-Blanco, I.; Lopez-Quintela, M. A. One-step synthesis of gold and silver hydrosols using poly $(\mathrm{N}$ vinyl-2-pyrrolidone) as a reducing agent. Langmuir 2006, 22 (16), 7027-7034

(36) Shi, J. P.; Xu, B.; Sun, X.; Ma, C. Y.; Yu, C. P.; Zhang, H. W. Light induced toxicity reduction of silver nanoparticles to Tetrahymena pyriformis: Effect of particle size. Aquat. Toxicol. 2013, 132, 53-60.

(37) Korgel, B. A.; Fitzmaurice, D. Self-assembly of silver nanocrystals into two-dimensional nanowire arrays. Adv. Mater. 1998, 10 (9), 661-665.

(38) Kaczmarek, H.; Kaminska, A.; Swiatek, M.; Rabek, J. F. Photooxidative degradation of some water-soluble polymers in the presence of accelerating agents. Angew. Makromol. Chem. 1998, 262, 109-121.

(39) Cai, L.; Tong, M.; Ma, H.; Kim, H. Cotransport of titanium dioxide and fullerene nanoparticles in saturated porous media. Environ. Sci. Technol. 2013, 47 (11), 5703-5710.

(40) Aiken, G. R.; Hsu-Kim, H.; Ryan, J. N. Influence of dissolved organic matter on the environmental fate of metals, nanoparticles, and colloids. Environ. Sci. Technol. 2011, 45 (8), 3196-3201.

(41) Nason, J. A.; McDowell, S. A.; Callahan, T. W. Effects of natural organic matter type and concentration on the aggregation of citratestabilized gold nanoparticles. J. Environ. Monit. 2012, 14 (7), 18851892.

(42) Stankus, D. P.; Lohse, S. E.; Hutchison, J. E.; Nason, J. A. Interactions between natural organic matter and gold nanoparticles stabilized with different organic capping agents. Environ. Sci. Technol. 2011, 45 (8), 3238-3244.

(43) Poda, A. R.; Kennedy, A. J.; Cuddy, M. F.; Bednar, A. J. Investigations of UV photolysis of PVP-capped silver nanoparticles in the presence and absence of dissolved organic carbon. J. Nanopart. Res. 2013, 15 (5).

(44) Maurer, F.; Christl, I.; Hoffmann, M.; Kretzschmar, R. Reduction and reoxidation of humic acid: Influence on speciation of cadmium and silver. Environ. Sci. Technol. 2012, 46 (16), 8808-8816.

(45) Xiu, Z. M.; Zhang, Q. B.; Puppala, H. L.; Colvin, V. L.; Alvarez, P. J. J. Negligible particle-specific antibacterial activity of silver nanoparticles. Nano Lett. 2012, 12 (8), 4271-4275.

(46) Xiu, Z. M.; Ma, J.; Alvarez, P. J. J. Differential effect of common ligands and molecular oxygen on antimicrobial activity of silver nanoparticles versus silver ions. Environ. Sci. Technol. 2011, 45 (20), 9003-9008.

(47) Choi, O.; Hu, Z. Q. Size dependent and reactive oxygen species related nanosilver toxicity to nitrifying bacteria. Environ. Sci. Technol. 2008, 42 (12), 4583-4588. 
(48) Liu, W.; Wu, Y.; Wang, C.; Li, H. C.; Wang, T.; Liao, C. Y.; Cui, L.; Zhou, Q. F.; Yan, B.; Jiang, G. B. Impact of silver nanoparticles on human cells: Effect of particle size. Nanotoxicology 2010, 4 (3), 319330.

(49) Zhao, C. M.; Wang, W. X. Size-dependent uptake of silver nanoparticles in Daphnia magna. Environ. Sci. Technol. 2012, 46 (20), 11345-11351.

(50) Jin, X.; Li, M. H.; Wang, J. W.; Marambio-Jones, C.; Peng, F. B.; Huang, X. F.; Damoiseaux, R.; Hoek, E. M. V. High-throughput screening of silver nanoparticle stability and bacterial inactivation in aquatic media: Influence of specific ions. Environ. Sci. Technol. 2010, 44 (19), 7321-7328.

(51) Li, X.; Lenhari, J. J.; Walker, H. W. Aggregation kinetics and dissolution of coated silver nanoparticles. Langmuir 2012, 28 (2), 1095-1104.

(52) Li, X. A.; Lenhart, J. J.; Walker, H. W. Dissolution-accompanied aggregation kinetics of silver nanoparticles. Langmuir 2010, 26 (22), 16690-16698.

(53) Huynh, K. A.; Chen, K. L. Aggregation kinetics of citrate and polyvinylpyrrolidone coated silver nanoparticles in monovalent and divalent electrolyte solutions. Environ. Sci. Technol. 2011, 45 (13), 5564-5571.

(54) Levard, C.; Mitra, S.; Yang, T.; Jew, A. D.; Badireddy, A. R.; Lowry, G. V.; Brown, G. E., Jr. Effect of chloride on the dissolution rate of silver nanoparticles and toxicity to E. coli. Environ. Sci. Technol. 2013, 47 (11), 5738-5745.

(55) Levard, C.; Reinsch, B. C.; Michel, F. M.; Oumahi, C.; Lowry, G. V.; Brown, G. E. Sulfidation processes of PVP-coated silver nanoparticles in aqueous solution: Impact on dissolution rate. Environ. Sci. Technol. 2011, 45 (12), 5260-5266.

(56) Reinsch, B. C.; Levard, C.; Li, Z.; Ma, R.; Wise, A.; Gregory, K. B.; Brown, G. E., Jr.; Lowry, G. V. Sulfidation of silver nanoparticles decreases Escherichia coli growth inhibition. Environ. Sci. Technol. 2012, 46 (13), 6992-7000.

(57) Akaighe, N.; Depner, S. W.; Banerjee, S.; Sharma, V. K.; Sohn, $M$. The effects of monovalent and divalent cations on the stability of silver nanoparticles formed from direct reduction of silver ions by Suwannee River humic acid/natural organic matter. Sci. Total Environ. 2012, 441, 277-289.

(58) Isaacson, C.; Zhang, W.; Powell, T.; Ma, X.; Bouchard, D. Temporal changes in aqu/C-60 physical-chemical, deposition, and transport characteristics in aqueous systems. Environ. Sci. Technol. 2011, 45 (12), 5170-5177.

(59) Isaacson, C. W.; Bouchard, D. C. Effects of humic acid and sunlight on the generation and aggregation state of aqu/C-60 nanoparticles. Environ. Sci. Technol. 2010, 44 (23), 8971-8976.

(60) Schwyzer, I.; Kaegi, R.; Sigg, L.; Smajda, R.; Magrez, A.; Nowack, B. Long-term colloidal stability of 10 carbon nanotube types in the absence/presence of humic acid and calcium. Environ. Pollut. 2012, 169, 64-73.

(61) Blaser, S. A.; Scheringer, M.; MacLeod, M.; Hungerbuhler, K. Estimation of cumulative aquatic exposure and risk due to silver: Contribution of nano-functionalized plastics and textiles. Sci. Total Environ. 2008, 390 (2-3), 396-409. 